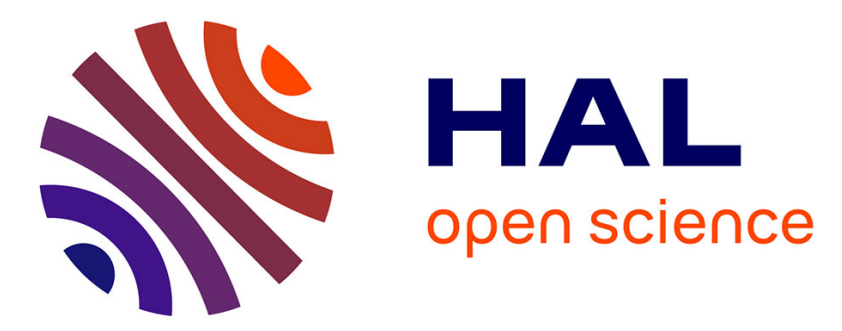

\title{
Base-Free Generation of Organic Electron Donors from Air-Stable Precursors
}

Guillaume Tintori, Pierre Nabokoff, Ruqaya Buhaibeh, David Bergé-Lefranc, Sébastien Redon, Julie Broggi, Patrice Vanelle

\section{- To cite this version:}

Guillaume Tintori, Pierre Nabokoff, Ruqaya Buhaibeh, David Bergé-Lefranc, Sébastien Redon, et al.. Base-Free Generation of Organic Electron Donors from Air-Stable Precursors. Angewandte Chemie International Edition, 2018, Angewandte Chemie International Edition, 57 (12), pp.31483153. 10.1002/anie.201713079 . hal-02079702

\section{HAL Id: hal-02079702 \\ https://hal-amu.archives-ouvertes.fr/hal-02079702}

Submitted on 18 Feb 2021

HAL is a multi-disciplinary open access archive for the deposit and dissemination of scientific research documents, whether they are published or not. The documents may come from teaching and research institutions in France or abroad, or from public or private research centers.
L'archive ouverte pluridisciplinaire HAL, est destinée au dépôt et à la diffusion de documents scientifiques de niveau recherche, publiés ou non, émanant des établissements d'enseignement et de recherche français ou étrangers, des laboratoires publics ou privés. 


\title{
Base-free generation of organic electron donors
}

\section{from air-stable precursors}

\author{
Guillaume Tintori, ${ }^{a[a]}$ Pierre Nabokoff, ${ }^{a[a]}$ Ruqaya Buhaibeh, ${ }^{[a]}$ David Bergé-Lefranc, ${ }^{[b]}$ Sébastien \\ Redon, ${ }^{[a]}$ Julie Broggi ${ }^{* a]}$ and Patrice Vanelle ${ }^{\star[a]}$
}

\begin{abstract}
Organic electron donors (OEDs) are powerful reducing agents recognized for their potential in the reduction of challenging substrates and in original applications. Nonetheless, their stability issues in atmospheric oxygen or over time complicate their manipulation and storage. To overcome these constraints and enhance OED's practicality, new air- and moisture-stable aminopyridinium carboxylate and carbonate precursors were synthesized and thermally activated to in-situ generate the potent electron donor. Carboxylate adducts proved to be excellent OEDlatent systems allowing easy and efficient reduction of challenging substrates. Their reducing properties are correlated to their structural characteristics by thermogravimetric and spectrometric analysis.
\end{abstract}

Organic electron donors (OEDs) with exceptionally negative redox potentials showed their potency and chemoselectivity in the reduction of challenging substrates. ${ }^{1}$ They promote the formation of radical or anionic intermediates by single- or double-electron transfers. ${ }^{2}$ These strong reducing agents are now attracting more and more the interest for original applications in diverse domains (coupling partners, polymerization initiators, redox switches, greenhouse gas reduction). ${ }^{3}$ Their structures usually consist of two aza-cycles, such as imidazole or pyridine rings, connected at their center by an electron-rich double bond (Scheme 1). Typically, the enamine is prepared by addition of a strong base (NaH, KHMDS) on the cyclic iminium precursor salt. Some enamines (such as OED-2, Scheme 2) are stable under inert atmosphere and can be stored and manipulated in a glove box. ${ }^{4}$ In other cases, the dimeric form is elusive (OED-1 has a half-life time of few minutes) and is rapidly converted into the corresponding carbene $(\mathbf{C b}-\mathbf{1}) .^{5}$ Thanks to the great resonance stabilization of their oxidized forms, pyridine and imidazole derivatives are powerful reducing agents with $\mathrm{E}_{1 / 2}\left(\right.$ OED-2) $=-1.27 \mathrm{~V}$ and $\mathrm{E}_{1 / 2}($ OED-1) $\approx-1.20 \mathrm{~V}$ vs. SCE. To deal with stability issues, one solution is to in-situ generate the electron donor from the iminium salt in the presence of the substrate to be reduced. However, the concomitant use of excess amount of strong base is problematic as it presents limited tolerance to various functionalities and often gives complex mixtures.

To overcome these constraints and enhance OED's

[a] G. Tintori, P. Nabokoff, R. Buhaibeh, Dr. S. Redon, Dr. J. Broggi, Prof. P. Vanelle

Aix-Marseille Univ, CNRS, Institut de Chimie Radicalaire ICR Faculté de Pharmacie,

Marseille, France.

E-mail: julie.broggi@univ-amu.fr; patrice.vanelle@univ-amu.fr.

${ }^{a}$ Both authors contributed equally to this work.

[b] Dr. D. Bergé-Lefranc

Aix-Marseille Univ, CNRS, IRD, Laboratoire IMBE UMR 7263

Faculté de Pharmacie,

Marseille, France.

Supporting information for this article is given via a link at the end of the document. practicality, new strategies based on the activation of air- and moisture-stable masked OED-systems are crucial for the easy and efficient generation of organic reducers (Scheme 1). Our choice went to the use of carboxylate and carbonate adducts, well-known carbene precursors. ${ }^{6}$ The advantage of these adducts is that any types of structures are virtually accessible by reaction of free $\mathrm{N}$-heterocyclic carbenes $(\mathrm{NHC})$ with $\mathrm{CO}_{2}$ atmosphere or by anion metathesis of azolium halides. Their thermolysis in-situ regenerate the free $\mathrm{NHCs}$ by decarboxylation, and $\mathrm{CO}_{2}$ is the only byproduct. This study proves that organic electron donors can also be formed during the process of thermal activation of carboxylate and carbonate adducts.

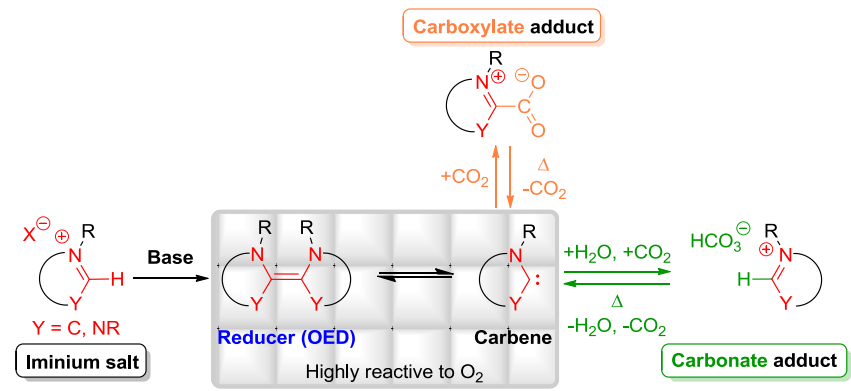

Scheme 1. In-situ generation of OEDs.

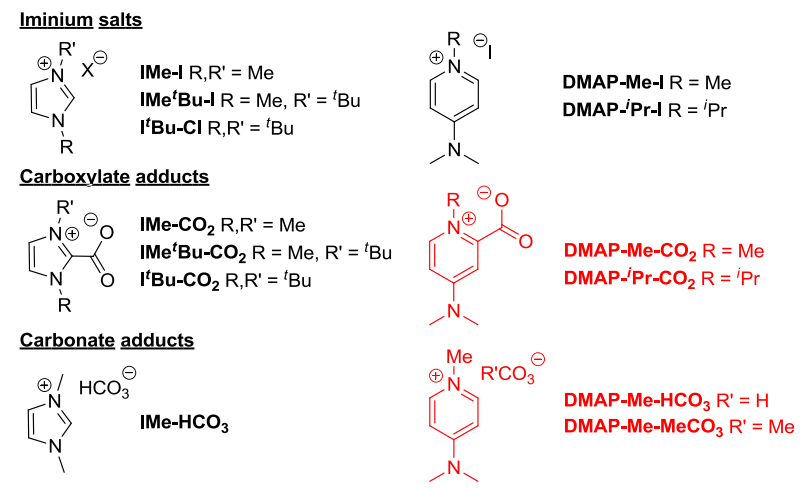

Figure 1. OED-precursors used in this study (new structures in red).

\section{Synthesis and characterization of OED-precursors}

All new carboxylate and carbonate precursors of pyridinylidenetype reducers (DMAP-series) were synthesized in good yields using similar strategies than the ones reported for imidazoliumbased carboxy adducts (I-series in Figure 1) ${ }^{7,8}$ Functionalization of the dimethylamino-pyridine core (DMAP) was obtained by a two-step procedure involving the deprotonation of the pyridinium 
From IMe- $\mathrm{CO}_{2}$

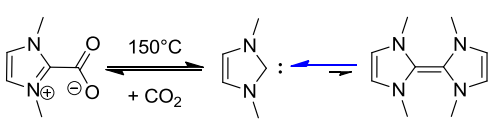

$\mathrm{IMe}-\mathrm{CO}_{2}$

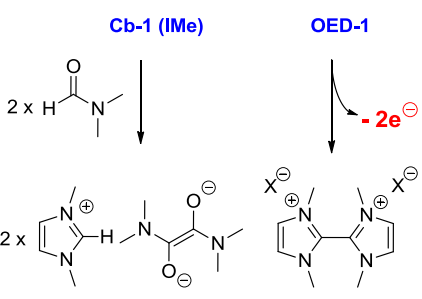

Formamide-derived OED

OED-1 $1^{2+}$

$$
\downarrow-2 e^{\ominus}
$$

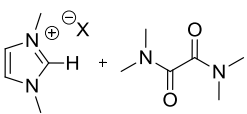

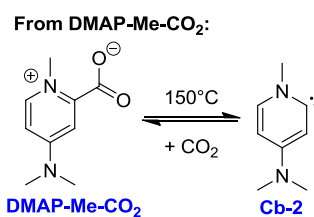

DMAP-Me-CO

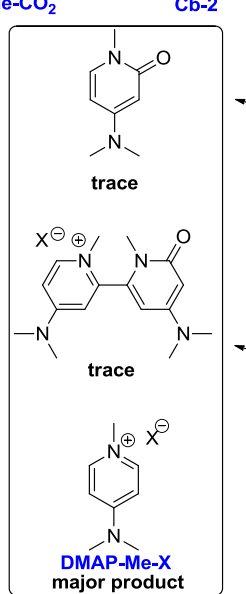

major product

Compounds retrieved in the aqueous phase

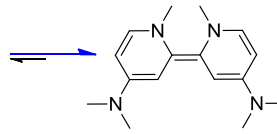

OED-2
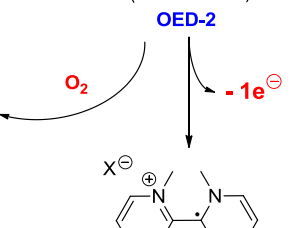

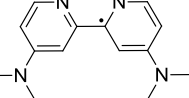
OED-2.+

$\int_{-1 e^{\ominus}}^{O E D-2}$

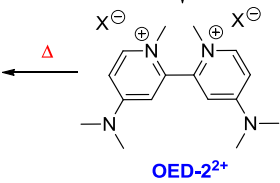

Scheme 3. Preparation of DMAP-derived carboxylate and carbonate precursors.

Structures of DMAP-Me-CO $\mathbf{C}_{2}$, DMAP. ${ }^{i} \mathrm{Pr}-\mathrm{CO}_{2}$ and DMAP-Me- $\mathrm{HCO}_{3}$ were confirmed by single crystal X-ray crystallography and compared to the data reported for the imidazolium counterparts (Table 1 and 2). ${ }^{8,10}$ Louie demonstrated that imidazolium carboxylates had a great resonance stabilization when the $\mathrm{CO}_{2}$ lay in the same plane as the imidazolium ring. On the other hand, an increase in $\mathrm{N}$-substituent size clearly induced longer $\mathrm{C}-\mathrm{CO}_{2}$ bond and higher torsional angles, thus causing decreased stability of the $\mathrm{NHC}-\mathrm{CO}_{2}$ and lower decarboxylation temperatures. In our case, the $\mathrm{C}-\mathrm{CO}_{2}$ bond lengths of DMAP-Me$\mathbf{C O}_{2}$ and DMAP-'Pr-CO${ }_{2}$ (1.53 $\AA$ and 1.529 $\AA$, respectively) were longer than in IMe$\mathbf{C O}_{2}(1.523 \AA)$ but shorter than in $\mathbf{I}^{\mathbf{t}} \mathbf{B u}-\mathbf{C O}_{\mathbf{2}}$ $(1.551 \AA)$. As well, the carboxylate torsional

Scheme 2. Potential species generated upon thermal decarboxylation and electron transfers.

salt followed by trapping of the generated species with carbon dioxide (Scheme 3). Whereas deprotonation of the 1,3-dimethylimidazolium iodide IMe-I with KHMDS gave the carbene $\mathbf{C b}-\mathbf{1}$, the dimeric OED-2 was the only product isolated upon deprotonation of the pyridinium DMAP-Me-I. This further confirms the stability of bispyridinylidenes, even $\mathrm{N}$-unbridged, compared to the elusive nature of imidazole-derived tetraazafulvalene (Scheme 2). ${ }^{4,5}$ Addition of $\mathrm{CO}_{2}$ on OED-2 afforded DMAP-Me- $\mathrm{CO}_{2}$. Note that carboxylation of an aminoethylene functional group and formation of pyridinium carboxylates was not previously reported in the literature. Contrary to $\mathrm{N}$-alkyl imidazolium carbonate, the $\mathrm{N}$-methyl pyridinium carbonate DMAP-Me-HCO $\mathrm{H}_{3}$ could not be directly obtained from the reaction of the carboxylate DMAP-Me- $\mathrm{CO}_{2}$ with water. Such lack of reactivity had been previously observed for $\mathrm{N}$-aryl imidazolium carboxylates, where $\mathrm{H}_{2} \mathrm{O}$ was suspected of being only hydrogen-bonded to the $\mathrm{CO}_{2}$ moiety. ${ }^{8}$ DMAP-Me$\mathrm{HCO}_{3}$ was obtained by initial methylation of the DMAP with dimethyl carbonate $\left((\mathrm{MeO})_{2} \mathrm{CO}\right)$ followed by hydrolysis of the methyl carbonate anion of DMAP-Me- $\mathrm{MeCO}_{3}$. Acid-base reaction between the methyl carbonate anion and the pyridinium cation to form DMAP-Me- $\mathbf{C O}_{2}$ was not observed. Carbonate adducts usually present higher moisture stability and are thus more convenient to store. ${ }^{9}$

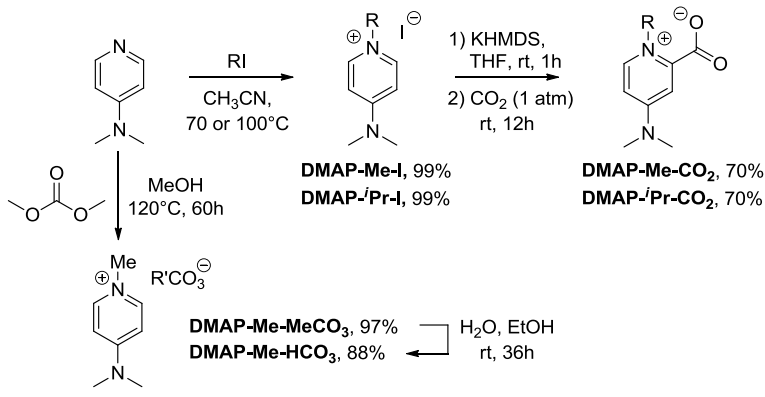

angles with respect to the iminium ring were significantly more pronounced in the DMAP derivatives $\left(90.84^{\circ}\right.$ and $77.61^{\circ}$,

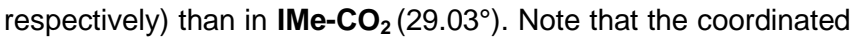
$\mathrm{CO}_{2}$ moiety in DMAP-Me- $\mathbf{C O}_{2}$ is perpendicular to the sixmembered pyridinium ring plane. Such a high dihedral angle had only been observed in the highly $\mathrm{N}$-hindered $\mathrm{IPr}-\mathrm{CO}_{2}(\mathrm{Pr}=2,6$ diisopropylphenyl, 88.14 ${ }^{\circ} .^{8}$ Carbonyl stretching frequencies of DMAP-Me- $\mathbf{C O}_{2}$ and DMAP-'Pr- $\mathbf{C O}_{2}$ followed the same trend, displaying an intermediate frequency of $1624 \mathrm{~cm}^{-1}$, between IMe- $\mathrm{CO}_{2}$ and ${ }^{t} \mathrm{Bu}-\mathrm{CO}_{2}$. These encouraging structural factors pointed toward a straightforward decarboxylation process for our novel DMAP carboxylates, similar to that of $\mathrm{N}$-hindered $\mathrm{NHC}$ $\mathrm{CO}_{2}$.

Table 1. X-ray and structural features of $\mathrm{NHC}-\mathrm{CO}_{2}$.

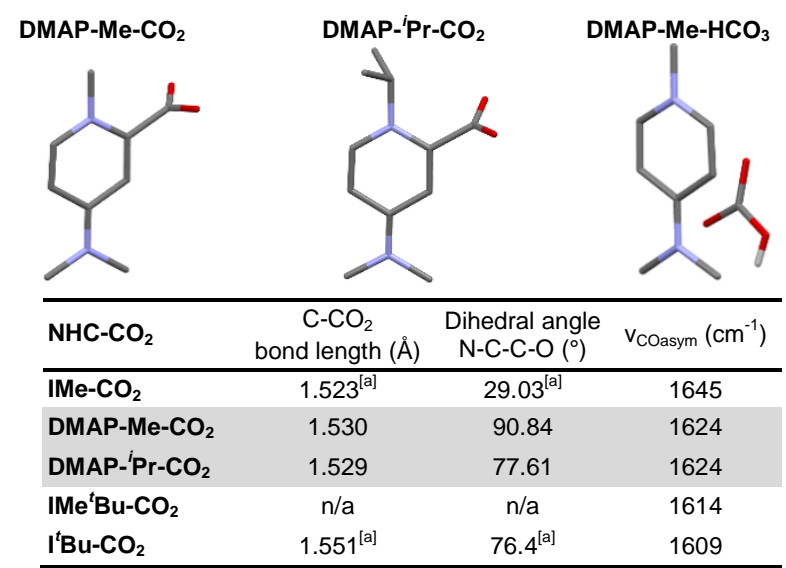

[a] Data excerpted from reference 8 and 10.

Table 2. Decarboxylation temperatures of carboxylate and carbonate precursors.

\begin{tabular}{lclc}
\hline IRR' adduct & $-\mathrm{CO}_{2 \text { temp }}\left({ }^{\circ} \mathrm{C}\right)$ & DMAP-R adduct & $-\mathrm{CO}_{2}$ temp $\left({ }^{\circ} \mathrm{C}\right)$ \\
\hline $\mathrm{IMe}^{-} \mathrm{CO}_{2}$ & 140 & DMAP-Me-CO & 181 \\
$\mathrm{IMe}_{2}-\mathrm{HCO}_{3}$ & 40,130 & DMAP-Me-HCO & 55,117 \\
$\mathrm{IMe}^{t} \mathrm{Bu}-\mathrm{CO}_{2}$ & 113 & DMAP-Me-MeCO & 34,110
\end{tabular}


$\mathrm{I}^{\mathrm{t}} \mathrm{Bu}-\mathrm{CO}_{2}$

63

DMAP-'Pr- $\mathrm{CO}_{2}$

103

Thermogravimetric analysis (TGA) further confirmed these conclusions showing intermediate decarboxylation temperatures for pyridinium derivatives (DMAP-Me- $\mathrm{HCO}_{3}: 117^{\circ} \mathrm{C}$, DMAP-Me$\mathrm{MeCO}_{3}: 110^{\circ} \mathrm{C}$, DMAP- ${ }^{\prime} \mathrm{Pr}-\mathrm{CO}_{2}: 103^{\circ} \mathrm{C}$, Table 2 and Figure S1S2). ${ }^{11}$ The first phenomena observed at 40,55 and $34^{\circ} \mathrm{C}$ for $\mathrm{IMe}^{-\mathrm{HCO}_{3}}$, DMAP-Me-HCO ${ }_{3}$ and DMAP-Me-MeCO corresponded to the prior loss of a molecule of $\mathrm{H}_{2} \mathrm{O}$ or $\mathrm{MeOH}$ (10, 6 and $15 \%$ of mass loss, respectively). Surprisingly, DMAP$\mathrm{Me}-\mathrm{CO}_{2}$ presented a much higher decomposition temperature $\left(181^{\circ} \mathrm{C}\right)$. Its crystalline structure displays an orthorhombic cell with a perfect alignment of the amino-pyridiniums compared to the monoclinic crystalline structures of DMAP- ${ }^{\prime} \mathbf{P r}-\mathbf{C O}_{2}$ and DMAP-Me- $-\mathrm{HCO}_{3} .{ }^{11}$ The well-organized arrangement of DMAP$\mathrm{Me}-\mathrm{CO}_{2}$ improves atom interactions and confers a particular rigidity to the solid that might explain its higher thermal resistance by TGA. The crystallographic program PLATONC confirmed the presence of twice hydrogen bond interactions in DMAP-Me- $\mathrm{CO}_{2}$ compared to DMAP-'Pr- $\mathrm{CO}_{2}$ and DMAP-Me$\mathrm{HCO}_{3} .{ }^{11}$ In solution, however, DMAP-Me- $\mathrm{CO}_{2}$ have a better reactivity at $120^{\circ} \mathrm{C}$ than DMAP-'Pr- $\mathbf{C O}_{2}$ (vide infra Table 4, entry 8 vs. 11). ${ }^{12}$ Given the low steric bulk around the $\mathrm{CO}_{2}$ unit, the breakability of the $\mathrm{C}-\mathrm{CO}_{2}$ bond in amino-pyridinium carboxylates seemed more related to the electronic influence of the aminopyridine ring rather than the steric effect of the $\mathrm{N}$-substituent. As a matter of fact, introduction of the bulkier isopropyl group (DMAP-'Pr- $\mathbf{C O}_{2}$ ) had little impact on the structural features and the decarboxylation temperature. Unfortunately, preparation of a tert-butyl analog, for the observation of a possible combined electronic and steric effect, failed.

\section{Comparative study for the reduction of 1}

Different temperatures of decarboxylation were first compared using the readily accessible and well-documented 1,3-dimethylimidazolium-2-carboxylate $\left(\mathrm{IMe}-\mathrm{CO}_{2}\right)^{7}$ as OEDprecursor (Table 3). Below $150^{\circ} \mathrm{C}$, reduction of the 1-iodo-2-(3phenoxypropyl)benzene 1 , a benchmark substrate in OEDpromoted reduction, was zero or close to it (Entries 1-2) even assisted by microwave irradiations (Entry 3). ${ }^{13}$ At $150^{\circ} \mathrm{C}$, a good conversion (74\%) into the reduced product 2 was observed (Entry 4). This temperature threshold is of the same order as the decarboxylation temperature measured by TGA for $\mathbf{I M e}-\mathbf{C O}_{2}$ (Table 2). The drastic fall in conversion rate $(19 \%)$ in a sealed system also confirmed the necessity for the loss of the $\mathrm{CO}_{2}$ gas (Entry 5). For a complete reduction of $\mathbf{1}$, several options were possible (for details see Table S1 in supporting information): i) the reaction time could be lengthened to $48 \mathrm{~h}$; ii) the quantity of precursor could be increased to 6 equivalents; iii) the flask could be purged with vacuum $/ \mathrm{N}_{2}$ cycles performed at $150^{\circ} \mathrm{C}$ at the beginning of the reaction. This vacuum effect, certainly leading to better removal of the $\mathrm{CO}_{2}$, was not sufficient to decrease the reaction temperature or the precursor equivalents; iv) the solvent concentration could be increased to $0.08 \mathrm{M}$ (Table 3 , entry 6). This last option had a greater impact, allowing the reduction of IMe- $\mathbf{C O}_{2}$ loading to 3 equivalents (Entry 7 ). Note that the use of 3 equivalents of carboxylate adduct imply the in-situ generation of only 1.5 equivalents of OED with respect to the substrate. Even tough preparation of these reaction mixtures was performed in a glove-box for a more accurate comparative study, a full conversion was also obtained when the reaction was setup in air and degassed under $\mathrm{N}_{2}$ before heating (Entry 9).

Different carboxylate and carbonate adducts were then compared expecting that the easy decarboxylation profile of $\mathrm{N}$ hindered imidazolium carboxylates, such as $\mathbf{I}^{\mathbf{t}} \mathbf{B u}-\mathbf{C O}_{2}$, would allow the reduction of $\mathbf{1}$ at lower temperatures (Table 4). Unfortunately, a linear decrease in conversion rates was observed as the bulk of the $\mathrm{N}$-substituents increased (Entries 26). Knowing that the decarboxylation of these imidazolium adducts is not a problem at these working temperatures, ${ }^{8}$ the steric hindrance around the $\mathrm{N}_{2} \mathrm{C}$-carbon center seems to be a serious impediment to the generation of the corresponding OED dimeric form. As predicted by our structural analysis, aminopyridinium adducts, DMAP-Me- $\mathrm{CO}_{2}$ and DMAP- ${ }^{i} \mathbf{P r}-\mathrm{CO}_{2}$, were better candidates: At $120^{\circ} \mathrm{C}$, higher conversion rates were obtained (68 and 15\%, respectively - Entries 8 and 11) than with IMe- $\mathbf{C O}_{2}\left(6 \%\right.$ - Table 3, entry 2). Moreover, after $6 \mathrm{~h}$ at $150^{\circ} \mathrm{C}$, $90 \%$ conversion into 2 was reached with DMAP-Me- $\mathbf{C O}_{2}$ versus $36 \%$ for $\mathrm{IMe}-\mathrm{CO}_{2}$ (Entries 1 and 9 ).

Table 3. Optimization of the reduction of $1^{[a]}$

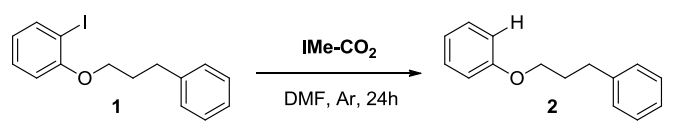

\begin{tabular}{ccccc}
\hline Entry & IMe-CO $_{2}$ (equiv.) & ${\text { Temp. }\left({ }^{\circ} \mathrm{C}\right)}$ & Concentration $\left(\mathrm{mol}^{-I^{-1}}\right)$ & Conv. $\left._{(\%}\right)^{[\mathrm{b}]}$ \\
\hline 1 & 5 & 80 & 0.04 & 0 \\
2 & 5 & 120 & 0.04 & 6 \\
3 & 5 & $120^{[\mathrm{c}]}$ & 0.04 & 6 \\
4 & 5 & 150 & 0.04 & 74 \\
5 & 5 & $150^{[\mathrm{d}]}$ & 0.04 & 19 \\
6 & 5 & 150 & 0.08 & $>99$ \\
7 & 3 & 150 & 0.08 & $>99(87)$ \\
8 & 2 & 150 & 0.08 & 78 \\
9 & 3 & $150^{[\mathrm{e}]}$ & 0.08 & 95 \\
\hline
\end{tabular}

[a] 1 (1 equiv.), IMe- $-\mathrm{CO}_{2}$ (2-5 equiv.), DMF (0.04 or $\left.0.08 \mathrm{M}\right), \mathrm{Ar}, 24 \mathrm{~h}$. [b] ${ }^{1} \mathrm{H}$ NMR conversion (isolated yield). [c] Microwave heating, 16h. [d] Closed schlenck. [e] Set-up in air and degassed under $\mathrm{N}_{2}$ before heating.

Table 4. Comparison of different carboxylate and carbonate precursors. ${ }^{[a]}$

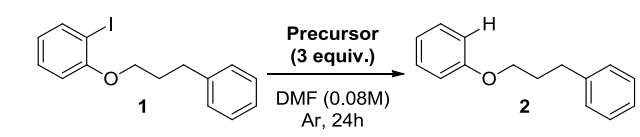

\begin{tabular}{|c|c|c|c|}
\hline Entry & Precursor & Temperature $\left({ }^{\circ} \mathrm{C}\right)$ & Conv. $(\%)^{[b]}$ \\
\hline 1 & $\mathrm{IMe}-\mathrm{CO}_{2}$ & 150 & $36^{[c]}$ \\
\hline 2 & $\mathrm{IMe}-\mathrm{CO}_{2}$ & 150 & $>99$ \\
\hline 3 & $\mathrm{IMe}^{t} \mathrm{Bu}-\mathrm{CO}_{2}$ & 120 & 0 \\
\hline 4 & $\mathrm{IMe}^{t} \mathrm{Bu}-\mathrm{CO}_{2}$ & 150 & 36 \\
\hline 5 & $\mathrm{I}^{t} \mathrm{Bu}-\mathrm{CO}_{2}$ & 70 & 0 \\
\hline 6 & $\mathrm{I}^{t} \mathrm{Bu}-\mathrm{CO}_{2}$ & 150 & 22 \\
\hline 7 & IMe-HCO ${ }_{3}$ & 150 & 59 \\
\hline 8 & DMAP-Me-CO & 120 & 68 \\
\hline 9 & DMAP-Me-CO & 150 & $90^{[c]}$ \\
\hline 10 & DMAP-Me-CO ${ }_{2}$ & 150 & $>99(80)$ \\
\hline 11 & DMAP-'Pr-CO ${ }_{2}$ & 120 & 15 \\
\hline 12 & DMAP-'Pr-CO ${ }_{2}$ & 150 & $>99$ \\
\hline
\end{tabular}




$\begin{array}{rlll}13 & \text { DMAP-Me-HCO } & 150 & 76 \\ 14 & \text { DMAP-Me-MeCO } & \\ 15 & \text { DMAP-Me-MeCO } & 120 & 42 \\ 3 & 150 & 88\end{array}$

[a] 1 (1 equiv.), precursor (3 equiv.), DMF (0.08 M), Ar, 24h. [b] ${ }^{1} \mathrm{H}$ NMR conversion (isolated yield). [c] Reaction time: $6 \mathrm{~h}$.

As expected from TGA, the impact of the bulkier $\mathrm{N}$-isopropyl group on the decarboxylation and reactivity of DMAP-i'Pr- $\mathbf{C O}_{2}$ (Entries 11-12) was not as evident as in imidazole series. Hydrogen carbonate adducts $I M e-\mathrm{HCO}_{3}$ and DMAP-Me- $\mathrm{HCO}_{3}$ could also be used as OED-precursors but they were less efficient than their carboxylate counterparts (Entries 7 and 13). DMAP-Me- $\mathbf{M e C O}_{3}$ gave a good percentage of product 2 (88\% Entry 15) but this carbonate salt was sensitive to water and rapidly decomposed into DMAP-Me- $\mathrm{HCO}_{3}$ upon exposure to air.

\section{Evidence supporting the involvement of an organic donor}

First, decarboxylation of the precursor is required as highlighted by the initiation of reactivity at high temperatures or inhibition of the reduction of $\mathbf{1}$ in closed systems (Table 3 ). This raises the question about the nature of the generated active species: carbene or enamine? Based on the preferential form adopted in the Wanzlick equilibrium upon deprotonation of the cyclic iminium salt, ${ }^{4,5}$ in-situ decarboxylation of IMe- $\mathrm{CO}_{2}$ should mainly lead to the formation of the carbene $\mathbf{C b}-\mathbf{1}$, while DMAPMe- $\mathrm{CO}_{2}$ should give OED-2 (Scheme 2). In the literature, there is no report on reaction of free carbenes on iodoarenes, ${ }^{14}$ while their reduction with organic reducers such as OED-1 and OED-2 is reported. ${ }^{4 \mathrm{~b}, 5 \mathrm{a}}$ Indeed, almost no reaction occurred using $\mathbf{C b}-\mathbf{1}$ at room temperature (Table 5, Entry 2), while reduction of $\mathbf{1}$ was complete using the powerful organic reducer OED-2 (Entry 1). Interestingly, at $150^{\circ} \mathrm{C}$, partial reduction of 1 was observed in the presence of Cb-1 (Entry 3). Two mechanisms could be considered starting from IMe- $\mathrm{CO}_{2}$ (Scheme 2): 1) At this high temperature, according to Van't Hoff law, the proportion of dimer OED-1 will be even lower than at room temperature. However, the electron transfer from OED-1 will be kinetically increased and could explain the progressive reduction of $\mathbf{1}^{5,15}$ 2) Deprotonation of the DMF by $\mathbf{C b}-\mathbf{1}$ leading to the formation of a formamide-derived electron donor could also be a competitive pathway for the electron transfer. ${ }^{16}$ The unfavorable formation of

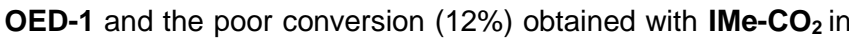
$\mathrm{N}, \mathrm{N}$-dimethylacetamide (DMA) ${ }^{17}$ (Table 5 , entry 5) would point mainly toward the formation of a formamide-derived OED.

Table 5. Mechanistic study. ${ }^{[a]}$

\begin{tabular}{|c|c|c|c|c|}
\hline Entry & Reducer & Equiv. & Temperature $\left({ }^{\circ} \mathrm{C}\right)$ & Conv. $(\%)^{[\mathrm{b}]}$ \\
\hline 1 & OED-2 & 1.5 & 25 & 96 \\
\hline 2 & $\mathrm{Cb}-1$ & 3 & 25 & $<4$ \\
\hline 3 & $\mathrm{Cb}-1$ & 3 & 150 & 66 \\
\hline $4^{[\mathrm{c}]}$ & DMAP-Me-CO ${ }_{2}$ & 3 & 150 & 99 \\
\hline $5^{[c]}$ & $\mathrm{IMe}^{-\mathrm{CO}_{2}}$ & 3 & 150 & 12 \\
\hline 6 & DMAP-Me-CO + TEMPO & $3+1.5$ & 150 & 59 \\
\hline 7 & DMAP-Me-CO ${ }_{2}+p$-DNB & $3+1.5$ & 150 & 18 \\
\hline 8 & DMAP-Me- $\mathrm{CO}_{2}+$ air & 3 & 150 & 38 \\
\hline
\end{tabular}

[a] 1 (1 equiv.), reducer (1.5 or 3 equiv.), DMF (0.08 M), Ar, 24h. [b] ${ }^{1} \mathrm{H}$ NMR conversion. [c] DMA $(0.08 \mathrm{M})$

A different mechanism appears to operate with DMAP-Me- $\mathbf{C O}_{2}$. The highly stable dimeric OED-2 is probably the major generated form. Conservation of the reactivity in DMA (Table 5, entry 4) excludes the formation of a formamide-derived OED. Evidences supporting the electron transfer mechanism were obtained with the addition of commonly used inhibitors. The reduction of 1 decreased to $59 \%$ in the presence of the radical trap TEMPO (2,2,6,6-tetramethyl-1-piperidinyloxy), 18\% with the competitive electron acceptor $p$-DNB (para-dinitrobenzene) and $38 \%$ when the reaction was carried out in air (Entries 6-8). Finally, analysis of the residual compounds at the end of the reaction confirmed the in-situ formation of the bispyridinylidene OED-2 (Scheme 2). The same dimethylamino-pyridinium salt DMAP-Me-X was recovered from the aqueous phase starting either from the active form OED-2 ${ }^{11}$ or the carboxylate precursor. This pyridinium salt DMAP-Me-X probably arise from the thermal decomposition of the oxidized form OED-2 ${ }^{2+}$. From a kinetic point of view, it seems that the first step of decarboxylation is the limiting step with a thermodynamic equilibrium between the OED-2 and the carboxylate form DMAP-Me- $\mathrm{CO}_{2} \cdot \mathrm{CO}_{2}$ remains in the DMF solution and competes with substrate $\mathbf{1}$ toward OED2. ${ }^{11}$

\section{Scope of the reaction}

To further investigate the versatility of our masked OED-system, the reduction of various substrates commonly used in OED promoted reactions was examined. ${ }^{1,18}$ To our delight, we totally and cleanly reduced aryl halide, sulfone, or sulfonamide derivatives (Scheme 4). Beside the required precursor's activation temperature, the potency of OED-2 was maintained using the same reaction conditions that previously reported (reducer loading, time, conversion). DMAP-Me- $\mathbf{C O}_{2}$ allowed the generation of OED-2 in the presence of the substrate, contrary to pre-formulated strong base/azolium salt solutions. ${ }^{5}$ In addition, the reaction could be conveniently set-up in air and degassed under $\mathrm{N}_{2}$ before heating. The few low isolated yields were attributed to the volatility of the reduced products. lodonaphtol and its acetate counterpart were not reduced, but both led to the recovery of iodonaphtol. The competitive nucleophilic nature of OED-2 $2^{1,19}$ certainly prevented the reduction in favor of the deprotonation of the alcohol or the deprotection of the acetate.

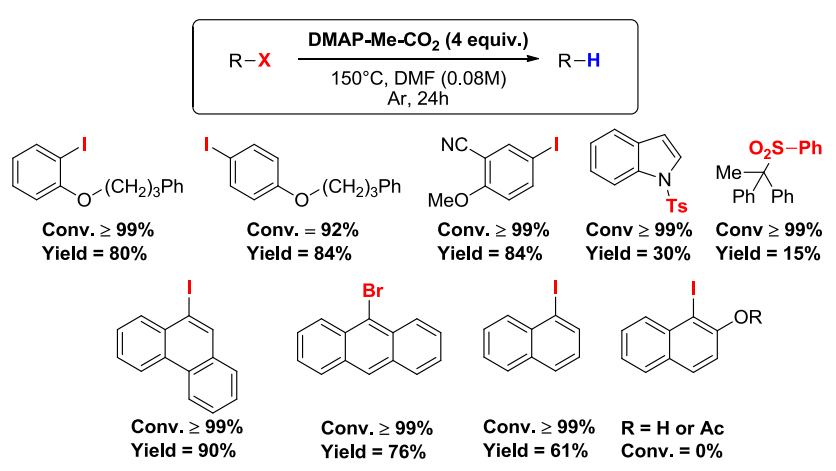

Scheme 4. Scope of the reaction. 
In conclusion, we presented here an original concept of base-free generation of organic electron donors from air- and moisture-stable precursors. Newly synthesized aminopyridinium carboxylate and carbonate adducts were fully characterized. They presented interesting structural and electronic properties compared to imidazolium series. These pyridinium carboxylate and carbonate adducts could also provide access to original pyridinylidene ligands in organometallic chemistry. In our case, the aminopyridinium carboxylates proved to be excellent OEDprecursors allowing the same order of reduction than the powerful organic reducers. These OED-masked systems will doubtless facilitate the handling of oxygen sensitive and elusive organic reducers and encourage their broader use. Work is now in progress to develop new OED-precursors with further enhanced functionality and practicality.

\section{Acknowledgements}

Aix-Marseille Université (AMU) and the Centre National de la Recherche Scientifique (CNRS) are gratefully acknowledged for financial support. G. T. thanks the Ministère de l'enseignement supérieur et de la recherche for his Ph.D. grant and P. N. thanks the Institut de Chimie Radicalaire for his master internship grant. We warmly thank Dr. Vincent Remusat for NMR analyses and the Spectropole (Fédération des Sciences Chimiques de Marseille) for MS, elemental analyses and X-ray determination. Our thanks to Michel Giorgi for valuable discussions on X-ray analysis.

Keywords: Electron transfer • organic electron donor • reduction reaction $\cdot$ carboxylate adduct $\cdot$ decarboxylation

[1] For reviews, see: a) J. Broggi, T. Terme, P. Vanelle, Angew. Chem 2014, 126, 392-423, Angew. Chem. Int. Ed. 2014, 53, 384-413; b) J.A. Murphy in Encyclopedia of Radicals in Chemistry, Biology and Materials (Eds.: C. Chatgilialoglu, A. Studer), Wiley-VCH, Weinheim, 2012; c) S. Zhou, H. Farwaha, J.A. Murphy, Chimia 2012, 66, 418-424 d) J.A. Murphy, J. Org. Chem. 2014, 79, 3731-3746; e) E. Doni, J.A. Murphy, Chem. Commun. 2014, 50, 6073-6087.

[2] a) S.S. Hanson, N.A. Richard, C.A. Dyker, Chem. Eur. J. 2015, 21 8052-8055; b) S.S. Hanson, E. Doni, K.T. Traboulsee, G. Coulthard, J.A. Murphy, C.A. Dyker, Angew. Chem. 2015, 127, 11388-11391, Angew. Chem. Int. Ed. 2015, 54, 11236-11239; c) H.S. Farwaha, G. Bucher J.A. Murphy, Org. Biomol. Chem. 2013, 11, 8073-8081; d) E. Doni, S. O'Sullivan, J.A. Murphy, Angew. Chem. 2013, 125, 2295-2298, Angew. Chem. Int. Ed. 2013, 52, 2239-2242; e) E. Doni, B. Mondal, S. O'Sullivan, T. Tuttle, J.A. Murphy, J. Am. Chem. Soc. 2013, 135 10934-10937; f) E. Cahard, F. Schoenebeck, J. Garnier, S.P.Y. Cutulic, S. Zhou, J.A. Murphy, Angew. Chem. 2012, 124, 3733-3736, Angew. Chem., Int. Ed. 2012, 51, 3673-3676.

[3] a) M. Rueping, P. Nikolaienko, Y. Lebedev, A. Adams, Green Chem. 2017, 19, 2571-2575; b) Y. Su, Y. Li, R. Ganguly, R. Kinjo Chem. Sci. 2017, 8, 7419-7423; c) F. Cumine, S. Zhou, T. Tuttle, J.A. Murphy, Org. Biomol. Chem. 2017, 15, 3324-3336; d) Y. Liu, J. Xu, J. Zhang, X. Xu, Z. Jin, Org. Lett. 2017, 19, 5709-5712; e) M. Li, S. Berritt, L. Matuszewski, G. Deng, A. Pascual-Escudero, G.B. Panetti, M. Poznik, X. Yang, J.J. Chruma, P.J. Walsh, J. Am. Chem. Soc. 2017, 139, 16327-16333; f) D. Munz, J. Chu, M. Melaimi, G. Bertrand, Angew. Chem. 2016, 128, 13078-13082, Angew. Chem. Int. Ed. 2016, 55,
12886-12890; g) J. Broggi, M. Rollet, J.L. Clément, G. Canard, T. Terme, D. Gigmes, P. Vanelle, Angew. Chem. 2016, 128, 6098-6103, Angew. Chem. Int. Ed. 2016, 55, 5994-5999; h) J.P. Barham, G. Coulthard, K. J. Emery, E. Doni, F. Cumine, G. Nocera, M.P. John, L.E.A. Berlouis, T. McGuire, T. Tuttle, J.A. Murphy, J. Am. Chem. Soc. 2016, 138, 7402-7410; i) J.P. Barham, G. Coulthard, R.G. Kane, N. Delgado, M.P. John, J.A. Murphy, Angew. Chem. 2016, 128, 45684572, Angew. Chem. Int. Ed. 2016, 55, 4492-4496; j) R. Rayala, A. Giuglio-Tonolo, J. Broggi, T. Terme, P. Vanelle, P. Theard, M. Médebielle, S.F. Wnuk, Tetrahedron 2016, 72, 1969-1977.

[4] a) J.A. Murphy, J. Garnier, S.R. Park, F. Schoenebeck, S.-Z. Zhou, A.T. Turner, Org. Lett. 2008, 10, 1227-1230; b) J. Garnier, J.A. Murphy, S.-Z. Zhou, A.T. Turner, Synlett 2008, 2127-2131.

[5] a) P.I. Jolly, S. Zhou, D.W. Thomson, J. Garnier, J.A. Parkinson, T Tuttle, J.A. Murphy, Chem. Sci. 2012, 3, 1675-1679; b) T.A. Taton, P. Chen, Angew. Chem. 1996, 108, 1098-1100, Angew. Chem., Int. Ed. Engl. 1996, 35, 1011-1013.

[6] a) L. Delaude, Eur. J. Inorg. Chem. 2009, 1681-1699; b) L. Yang, H. Wang, ChemSusChem 2014, 7, 962-998.

[7] a) J.D. Holbrey, W.M. Reichert, I. Tkatchenko, E. Bouajila, O. Walter, I. Tommasi, R.D. Rogers, Chem.Commun. 2003, 28-29; b) A.M. Voutchkova, M. Feliz, E. Clot, O. Eisenstein, R.H. Crabtree, J. Am Chem. Soc. 2007, 129, 12834-12846.

[8] B.R. Van Ausdall, J.L. Glass, K.M. Wiggins, A.M. Aarif, J. Louie, J. Org Chem. 2009, 74, 7935-7942.

[9] a) M. Fevre, J. Pinaud, A. Leteneur, Y. Gnanou, J. Vignolle, D. Taton, K. Miqueu, J.-M. Sotiropoulos, J. Am. Chem. Soc. 2012, 134, 6776-6784; b) M. Fevre, P. Coupillaud, K. Miqueu, J.-M. Sotiropoulos, J. Vignolle, D. Taton, J. Org. Chem. 2012, 77, 10135-10144.

[10] E. Theuergarten, T. Bannenberg, M.D. Walter, D. Holschumacher, M. Freytag, C.G. Daniliuc, P.G. Jones, M. Tamm, Dalton Trans. 2014, 43 1651-1662.

[11] See supporting information for more details.

[12] In solution, the decarboxylation temperature of carboxylate adducts is strongly influenced by the solvent polarity: D.M. Denning, D.E. Falvey J. Org. Chem. 2014, 79, 4293-4299.

[13] Note that our Biotage $\circledast$ Initiator microwave system operates with sealed vials, not allowing the $\mathrm{CO}_{2}$ evacuation.

[14] C-F Bond activation by NHC, leading to the nucleophilic aromatic substitution of highly activated perfluorinated arenes, is reported: $\mathrm{J}$. Emerson-King, S.A. Hauser, A.B. Chaplin, Org. Biomol. Chem. 2017, 15, 787-789 and references cited therein.

[15] Although formation of OED-1 is kinetically and thermodynamically unfavorable, evidences of the Wanzlick equilibrium in solution between enetetramine and carbene have been reported. a) R.W. Alder, M.E. Blake, L. Chaker, J.N. Harvey, F. Paolini, J. Schütz, Angew. Chem 2004, 116, 6020-6036, Angew. Chem. Int. Ed. 2004, 43, 5896-5911; b) F.E. Hahn, L. Wittenbecher, D. Le Van, R. Fröhlich, Angew. Chem. 2000, 112, 551-554, Angew. Chem. Int. Ed. 2000, 39, 541-544. The activation energy for the dimerization of Cb-1 was estimated at 23.4 kcal.mol ${ }^{-1}$, reduced to $15.9 \mathrm{kcal}^{\mathrm{mol}}{ }^{-1}$ under electrophilic catalysis; c) M. J. Cheng, C.-H. Hu, Chem. Phys. Lett. 2001, 349, 477-482; d) D.C. Graham, K.J. Cavell, B.F. Yates, J. Phys. Org. Chem. 2005, 18, 298309.

[16] For the formation of a DMF-derived organic donor upon deprotonation at $130^{\circ} \mathrm{C}$ with $\mathrm{KO}^{t} \mathrm{Bu}\left(\mathrm{p} K_{\mathrm{a}}\left(\mathrm{KO}^{t} \mathrm{Bu}\right.\right.$ in DMSO$)=29.4$ versus predicted $\mathrm{p} K_{\mathrm{a}}(\mathbf{C b}-\mathbf{1}$ in DMSO $)=21$, see reference $3 \mathrm{~h}$.

[17] N,N-Dimethylacetamide (DMA) does not allow the in-situ formation of OED upon its deprotonation.

[18] F. Schoenebeck, J.A. Murphy, S.-Z. Zhou, Y. Uenoyama, Y. Miclo, T. Tuttle, J. Am. Chem. Soc. 2007, 129, 13368-13369.

[19] N. Wiberg, Angew. Chem. 1968, 80, 809-822, Angew. Chem. Int. Ed. Engl. 1968, 7, 766-779. 
Layout 2:

\section{COMMUNICATION}

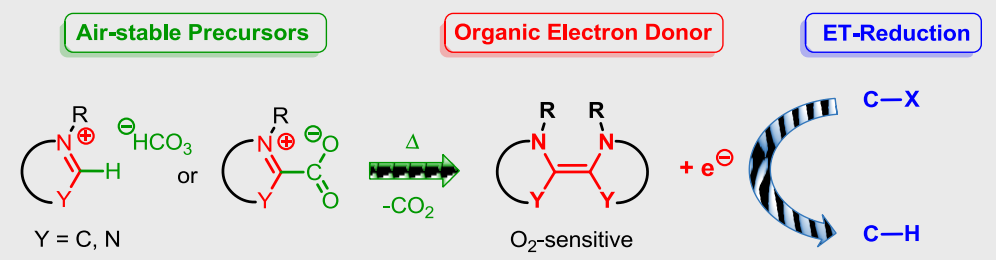

To enhance the practicality of organic electron donors (OED), new air- and moisture-stable carboxylate and carbonate precursors were synthesized and thermally activated to in-situ generate the potent electron donor. Carboxylate adducts proved to be excellent OED-latent systems, allowing the easy and efficient reduction of challenging substrates.
Guillaume Tintori, Pierre Nabokoff, Ruqaya Buhaibeh, David Bergé-Lefranc, Sébastien Redon, Julie Broggi* and Patrice Vanelle*

\section{Page No. - Page No.}

Base-free generation of organic electron donors from air-stable precursors 